\title{
Development of metakaolin and geopolymer proppants with nanocarbon materials
}

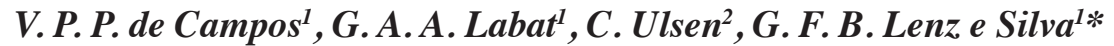 \\ ${ }^{1}$ Universidade de São Paulo, Escola Politécnica, Departamento de Engenharia Metalúrgica e de Materiais, \\ 5508-010, S. Paulo, SP, Brazil \\ ${ }^{2}$ Universidade de São Paulo, Escola Politécnica, Departamento de Engenharia de Minas e de Petróleo, \\ 5508-010, S. Paulo, SP, Brazil
}

\begin{abstract}
From the first hydraulic fracturing in the 40's until nowadays, the techniques of each process step have evolved significantly. This study presents a new approach on the development of metakaolin (MK) and geopolymer based proppant with and without nanocarbon materials such as multi-walled carbon nanotubes and graphene oxide. For manufacturing the microspheres, the chosen method was intensive mixing of raw material with dispersed nanocarbons followed by sintering metakaolin and curing the geopolymer using an alkaline medium $(\mathrm{NaOH})$. Compression mechanical tests, bulk density, turbidity, and $\mathrm{K} \& \mathrm{~S}$ method analysis were made following API RP 19C standard. The sample containing 4.3 M NaOH to produce alkali-activated metakaolin sintered at $1300{ }^{\circ} \mathrm{C}$ for $2 \mathrm{~h}$ presented higher mechanical resistance generating $2.4 \%$ of fines at $3 \mathrm{~K}$ (3000 psi). The geopolymer samples showed higher crushing strength and lower bulk density when compared to the MK samples without heat treatment. Furthermore, reduced graphene was produced and incorporated into activated MK. Morphology and presence of carbon nanostructures on the proppants were evaluated by scanning electron microscopy. Crushing test reached $3 \mathrm{~K}$ enabling it to be used as a ceramic synthetic proppant containing carbon nanomaterials.
\end{abstract}

Keywords: metakaolin, ceramic proppants, geopolymer, reduced graphene, nanomaterials, nanotechnology.

\section{INTRODUCTION}

Stanolind Co. performed the 'oil well shooting' techniques in 1860 and both 'well acidizing' and 'pressureparting' in the 1930s. However, the first hydraulic fracturing was performed by the same company in 1947 with an experimental treatment of reservoir stimulation called HydraFrac. The procedure was successful, however, the Halliburton Co. (Howoco) patented this procedure in 1949 [1]. The hydraulic fracturing technique is one of the most effective forms of extraction of oil and gas from unconventional reservoirs, where the hydrocarbons are trapped into the bituminous rocks. It consists of horizontal drilling, well protection (coating and cementation), internal explosion (gunner), application of high-pressure fracturing fluid, pressure removal and hydrocarbon collection [1-3]. The process can be summarized as it follows: i) estimate the stresses and the pressure; ii) determine the $\mathrm{F}_{\mathrm{CD}}$ (dimensionless fracture conductivity) and the FOI (folds of increase); iii) estimate the fracture geometry: Young's modulus and sand/shale $(\Delta \sigma)$; iv) fluid loss ' $\mathrm{C}$ ' coefficient and spurt loss; v) fluid selection-apparent viscosity (cps); vi) calibrate the model: stresses-diagnostic fracture injection test (DFIT) and fluid loss and efficiency-minifrac; vii) pressure history match; and viii) economics-refine job size: discounted return on investment (DROI), net present value $(\mathrm{NPV})$, fracture penetration $\left(\mathrm{x}_{\mathrm{f}}\right)$, injection rate $(\mathrm{Q})$,

*guilhermelenz@usp.br

(D) https://orcid.org/0000-0003-1184-5271 proppant concentration (PPG), proppant and fluid volume, and proppant type [1]. Thus, to transport the proppant inside the reservoir it is necessary to mix it with the fracturing fluid. In the fracturing fluid, the proppant is typically 0.5 wt $\%$ of the composition, while water is $90.0 \mathrm{wt} \%$ and chemical additives such as acids, stabilizers, corrosion inhibitors, friction reducers, and surfactants are $9.5 \mathrm{wt} \%$ [4]. The main role of the proppant is to ensure the hydrocarbon permeability granting high productivity of the well during its economic life. The proppants are injected with the fracturing fluid and then they penetrate into generated cracks. Usually, proppants are made by the sintering of high-grade bauxite or kaolin. High-grade bauxite is used because of its high mechanical strength after heat treatment. Such property is crucial for proppants at great depths due to the closure stress in the hydrocarbon region may exceed 8000 psi [5]. Therefore, most of the fabrication processes are done with a granulation technique [6] where the raw material (a fine powder between 45-80 $\mu \mathrm{m}$ of different compositions which generally contain silica, alumina, and iron) are added to an intensive mixer and the humidity is controlled in order to obtain the granulated material and then, the material can be classified and sintered. After sintering, the material goes through a new size classification and the proppant is obtained in the chosen range. During the process, the material may contain imperfections, some beads may become imperfect (size, shape and/or mechanical) and they could be used as abrasives or cement mortars. Moreover, the proppant must have some specific characteristics and properties for the frac job. 
There are many proppants already being used in the frac job and several others that are in development, such as: silica sand (SS), ceramic synthetic proppants (CSP): lightweight ceramics (LWC), intermediate ceramics (IDC), high-density ceramics (HDC) and ultra-high-strength proppant (UHSP); resin coated proppants (RCP), lightweight proppants (LWP) such as plastic beads, ultra-lightweight proppant (ULWP) such as nuts, seed shells and fruit pits [7], thermoplastic alloy (TPA), plastics, hollow glass spheres [8], advanced ceramic proppant [9], composite proppants, porous ceramics or silica sand core substrate coated with a particulate material [10], mineral industry waste based proppants as magnesium silicate [11, 12], red mud [13], and metakaolin/geopolymer based proppants $[14,15]$. Table I presents some of the most common characteristics of proppant types. For the complete characterization of the sand, the API series standards are used, mainly API RP 19C, and the main parameters used are: size distribution; K\&S (sphericity and roundness); density; solubility in acid media; turbidity; resistance to crushing and conductivity. Availability and conductivity requirements are proppant selection criteria standards which should be considered [17]. The properties of the proppants can vary in a broad range. However, the goal is always the same, to improve the hydrocarbon flow.

After the many above mentioned examples of development of special proppants it is important to highlight some studies involving nanotechnology such as [3]: use of single-walled carbon nanotubes (SWNTs) treated with gold and 4-amino-TEMPO molecules; contrasting nanoparticles that can be identified by nuclear magnetic resonance (NMR) or sensors obtained from nanomaterials or nanostructures, such as nanorobots, can be added in the fracturing fluid or transported in the proppants' pores; nanometric thin films for corrosion protection; carbon nanotubes used as coating materials; proppants made with nanosilica; alumina with empty core proppants in order to ensure high sphericity versus low-density ratio and controlled electrolytic materials (CEM) as raw material for proppants development [3]. Furthermore, the use of nanocarbons in cementitious materials has been carried out since 2004 [18] and in some studies, an increase of up to $50 \%$ in the compressive strength was observed [19]. In geopolymer materials, Goldoni and Pandolfo [20] obtained an increase of about $40 \%$ in flexural strength with the incorporation of carbon nanotubes (CNT) while Saafi et al. [21] obtained an increase of up to three times for flexural strength and verified the possibility of reducing the graphene oxide (GO) during the geopolymer production. Saafi et al. [22] also observed an increase of $209 \%$ in the electrical conductivity of the composite using $0.35 \mathrm{wt} \% \mathrm{GO}$. Thus, the use of carbon nanomaterials (CNM) for the development of proppants might represent an important step in research.

This work presents the manufacturing, process, and evaluation of metakaolin and geopolymer microspheres development with carbon nanomaterials incorporated. For manufacturing the microspheres, the chosen method was to intensive mixing the raw material with dispersed nanomaterials followed by sintering metakaolin and curing the geopolymer using an alkaline medium $(\mathrm{NaOH})$. The evaluation of samples was performed using the API RP 19C standard and their morphology was analyzed by SEM (scanning electron microscopy) which showed the possibility to incorporate carbon nanomaterials $(\mathrm{CNM})$ in a metakaolin proppant made by sintering and curing methods.

\section{MATERIALS AND METHODS}

The samples were split into two groups: metakaolin (MK); and geopolymer (GP). The MK group was chosen as a reference, in order to explore the $\mathrm{NaOH}$ use as a fluxing agent of sintering while the samples of GP group were developed according to the compositions presented in the literature [23] optimized by linear programing Solver to find an optimal composition value. The selected materials for this study were HP ultra-metakaolin (MK) with a composition of $57 \%$ of $\mathrm{SiO}_{2}$ and $34 \%$ of $\mathrm{Al}_{2} \mathrm{O}_{3}$, supplied by Metacaulim do Brasil which was used in all samples (MK and GP). Materials used for the MK production: in order to activate it, sodium hydroxide $(\mathrm{NaOH}$, analytic grade, $99 \%$ purity, microperl, Casa Americana) 4.3 molar (6 wt $\%$ used); water (granulation agent), approximately $35 \mathrm{wt} \%$; carbon nanotubes (CNT, Cheap Tubes USA, from China, industrial grade, $>95 \%$ carbon, $30-50 \mathrm{~nm}$ diameter, multiwalled, length of $10-20 \mu \mathrm{m}), 0.2 \mathrm{wt} \%$ used; and graphite for graphite oxide and reduced graphene $(\mathrm{RG})$ production from Nacional de Grafite, $99.98 \%$ purity, 0.003 wt $\%$ used. Materials used for the geopolymer (GP) production: alkaline sodium silicate (SS, from Diaton do Brasil, metakaolin activator); water; blast furnace slag, high $\mathrm{Al}_{2} \mathrm{O}_{3}$ concentration, from Usiminas Steelworks; sodium hydroxide; calcined alumina powder (from Almatis do Brasil, CAS 1344-28-1); carbon nanotubes, $0.2 \mathrm{wt} \%$ used; and graphite, $0.003 \mathrm{wt} \%$ used.

Table I - Summary of characteristics from different types of proppants $[3,16]$.

\begin{tabular}{ccccc}
\hline Proppant & $\begin{array}{c}\text { Specific density range } \\
\left(\mathrm{g} / \mathrm{cm}^{3}\right)\end{array}$ & $\begin{array}{c}\text { Year of technology } \\
\text { development }\end{array}$ & $\begin{array}{c}\text { Estimated price } \\
(\$ / \mathrm{klb})\end{array}$ & $\begin{array}{c}\text { Compressive strength } \\
\left(\mathrm{kpsi}-\mathrm{C}^{\prime}\right)\end{array}$ \\
\hline SS & 2.5 & 1947 & $19-58$ & $2-4$ \\
CSP & $2.5-4.0$ & 1983 & $270-900$ & $10-20$ \\
RCS (RCP) & $2.0-2.6$ & 1984 & $195-245$ & $2-7$ \\
LWP-ULWP & $0.8-2.5$ & - & $300-500$ & $2-10$ \\
\hline
\end{tabular}


Table II - Used materials and composition resume.

\begin{tabular}{|c|c|c|c|c|c|c|c|c|c|c|}
\hline Sample & $\begin{array}{c}\text { MK } \\
(\mathrm{g}) \\
\end{array}$ & $\begin{array}{l}\text { Water } \\
(\mathrm{mL})\end{array}$ & $\begin{array}{c}\mathrm{NaOH} \\
(\mathrm{g})\end{array}$ & $\begin{array}{l}\text { SS } \\
(\mathrm{g})\end{array}$ & $\begin{array}{c}\mathrm{Al}_{2} \mathrm{O}_{3} \\
(\mathrm{~g}) \\
\end{array}$ & $\begin{array}{l}\text { Slag } \\
(\mathrm{g})\end{array}$ & $\begin{array}{c}\text { CNT } \\
(\mathrm{g})\end{array}$ & $\begin{array}{l}\text { RG } \\
(\mathrm{g})\end{array}$ & $\begin{array}{l}\text { Mixing } \\
\text { time (s) }\end{array}$ & $\begin{array}{c}\text { Heat } \\
\text { treatment }\end{array}$ \\
\hline Pure MK & \multirow{4}{*}{2000.0} & 720 & 0 & \multirow{4}{*}{0} & \multirow{4}{*}{0} & \multirow{4}{*}{0} & 0 & & 420 & \multirow{4}{*}{$\begin{array}{c}\mathrm{RT} \text { and } \\
1300^{\circ} \mathrm{C} / 2 \\
\mathrm{~h}\end{array}$} \\
\hline $\mathrm{MK} 4.3 \mathrm{M}$ & & 700 & \multirow{3}{*}{120.0} & & & & 0 & 0 & 455 & \\
\hline MK 4.3 M CNT & & 820 & & & & & 4.0 & & 1200 & \\
\hline MK 4.3 M RG & & 790 & & & & & 0 & 0.015 & 153 & \\
\hline GP & & & & \multirow{3}{*}{129.0} & \multirow{3}{*}{39.0} & \multirow{3}{*}{259.5} & 0 & 0 & 498 & \multirow{3}{*}{$\begin{array}{c}\text { Cure for } 7 \\
\text { days }\end{array}$} \\
\hline GP CNT & 781.5 & 120 & 286.5 & & & & 4.0 & 0 & 300 & \\
\hline GP RG & & & & & & & 0 & 0.015 & 220 & \\
\hline
\end{tabular}

Nanocarbons (acquired commercial multilayer carbon nanotube and few layers of reduced graphite synthetized from graphene oxide by Hummers modified method) and reduced system aluminum powder/sodium hydroxide solution [14] were used and dispersed in metakaolin. All nanocarbons materials were dispersed by high energy mill mixing (SPEX $8000 \mathrm{M}$ ), for $10 \mathrm{~min}$ with 15 units of stainless-steel spheres with $4.5 \mathrm{~mm}$ diameter. The alkali solution for MK samples was performed stirring $120 \mathrm{~g}$ of sodium hydroxide in $200 \mathrm{~mL}$ of water in a polypropylene baker inside a room temperature water bath while GP solution was achieved by mixing $120 \mathrm{~mL}$ of water with $129 \mathrm{~g}$ of alkaline sodium silicate until the solubilization of sodium silicate, stirred during few seconds, with controlled water bath temperature. The MK sample production involved mixing $2.00 \mathrm{~kg}$ of metakaolin raw material at $60 \mathrm{~Hz}$ intensity during $10 \mathrm{~s}$ in an Eirich R02 high-intensity mixer equipped with a 'pinus' type spindle. Then, the previously prepared $\mathrm{NaOH}$ solution was added and mixed for $1 \mathrm{~min}$ at $60 \mathrm{~Hz}$ intensity. After this time, the intensity was dropped to $30 \mathrm{~Hz}$ and maintained at this frequency during at least $30 \mathrm{~s}$. When necessary, more water was added to the system. The process ended when the microspheres within the required size were observed, well defined and a small amount of powder remained on the bottom of the mixing stainless steel jar. Table II summarizes all compositions, mixing time and the heat treatment used in the MK and GP proppants with and without nanocarbon materials. The produced microspheres were classified, after mixing, using a 12 mesh Tyler sieve. The sample was sieved again in a high frequency vibrating equipment in the range of 20/40 mesh Tyler and, finally, cured for 7 days. After that, the MK samples were heat treated at $1300{ }^{\circ} \mathrm{C}$ for $2 \mathrm{~h}$. All samples with nanocarbon were sintered under an ultra-pure (99.999\% purity) argon flow atmosphere.

Characterization of the samples was performed according to the API RP 19C standard. The number of fines was evaluated and the value expressed in psi or ' $\mathrm{K}$ ', where $\mathrm{K}$ represents the abbreviated unit in kpsi, which is established when proppant is crushed at determined stress. According to this standard, the limit of fines generated for synthetic ceramic proppants should be a maximum of $10 \%$. The equipment used in this analysis was an Emic automated hydraulic press, mod. 23-300, with up to $300 \mathrm{kN}$ of capacity. The software
VirMaq was used for controlling the temperature. The press operation was performed using the TESC software. The hydraulic press was calibrated by the manufacturer with deviation in the measurements of approximately $1 \%$, as requested by the standard. The proppant 2" crushing test cell was manufactured with a Rockwell C 56 hardness stainless steel. The amount of crushed material was calculated as a percentage of fines of the mass of the proppant sample placed in the cell. Bulk density was calculated using the relation of the occupied material mass in a specific volume. The procedure was carried out using a $25 \mathrm{~mL}$ graduated cylinder completed by a 20/40 mesh size proppant. Turbidity test was performed to determine the amount of releasable or suspended particles in water. $50 \pm 20 \mathrm{~g}$ of sample was separated and $20 \pm 1 \mathrm{~mL}$ of the dried sample was measured in a beaker. The sample was placed in an Erlenmeyer flask and $100 \mathrm{~mL}$ of demineralized water was added. It was allowed to stand for $30 \mathrm{~min}$. Afterward, the material into the Erlenmeyer was vigorously manually shaken for $30 \mathrm{~s}$. After this mixing procedure, the turbidity was measured by a laser using a Hanna turbidity mod. HI98703-01. The value was provided in NTU (nephelometric turbidity unit). The net fraction was placed in the turbidimeter's unique flask and the analysis was performed 3 times by varying the position of the flask inside the equipment. Always care was taken not to touch, scratch or dirty the surface of the flask because any variation on this surface could cause an error in the reading of the signal generated by the emission of the laser. Krumbein \& Sloss (K\&S method, from Section 7.3 API RP 19C standard) characterization was focused on evaluating the shape of the proppant. For this method, $1 \mathrm{~g}$ of the sample and optical microscopy, Olympus BIXS, were used. A microphotograph of each sample, selecting 20 individual particles and comparing with the K\&S chart (Fig. 1) for roundness and sphericity degrees, was collected and an average value was determined. This value corresponded to the value of sphericity and rounding of the sample under analysis. The K\&S analysis was supported with optical microscopy images (Zeiss Stemi 2000-C with AxioCam ICc 3). The MK $4.3 \mathrm{M}$ with heat-treatment and GP samples were analyzed using a Camsizer XT equipment. It indicated how close the shape of the sample was to a sphere (sphericity) and how the sharpness of the grain corners was (roundness). 

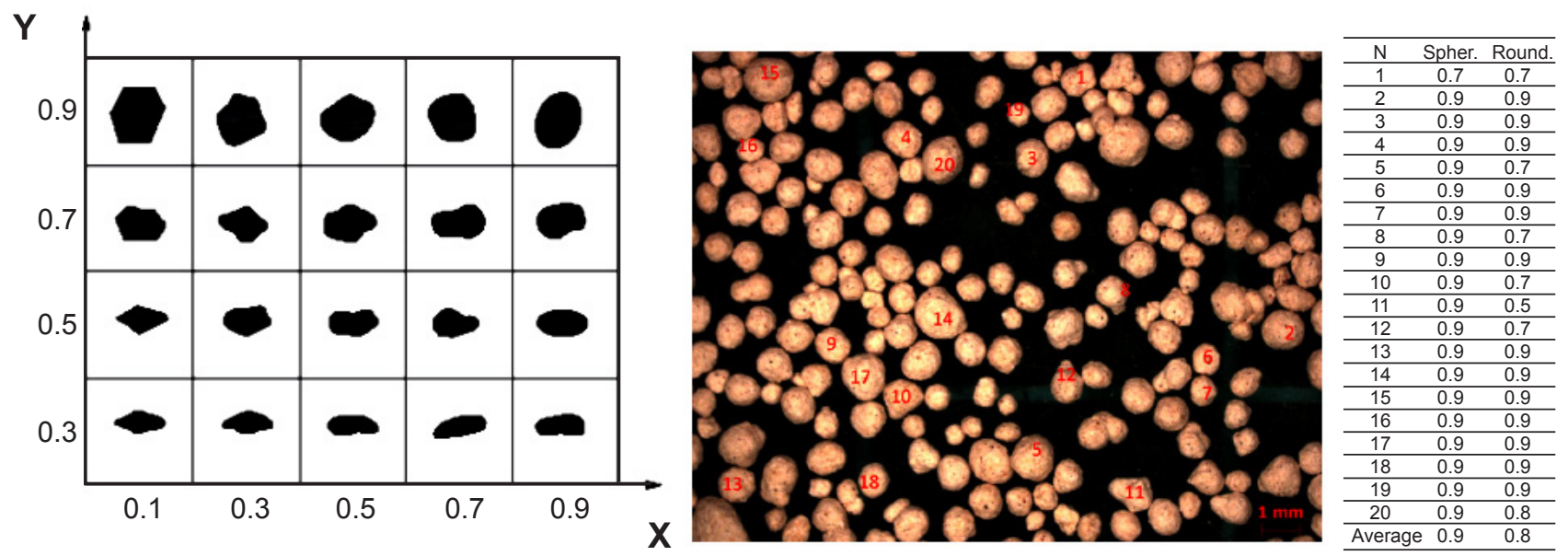

Figure 1: Example of photomicrography of the MK sample performed in the K\&S sphericity and rounding procedure.

Finally, after crushing test, the internal morphology of the crushed samples was analyzed by scanning electron microscopy (SEM, FEG, Inspect F50).

\section{RESULTS AND DISCUSSION}

Initially, the samples were characterized according to the K\&S (sphericity and roundness - Krumbein and Sloss) evaluation (Fig. 2). The minimum sphericity and rounding limit are 0.6 , according to the standard. Thereby, all samples were equal or above the $\mathrm{K} \& \mathrm{~S}$ limit. These values may also indicate the quality of the sample application. The values of sphericity and roundness found in the literature for the analysis of $\mathrm{K} \& \mathrm{~S}$ are 0.9 for sphericity and 0.8 for roundness

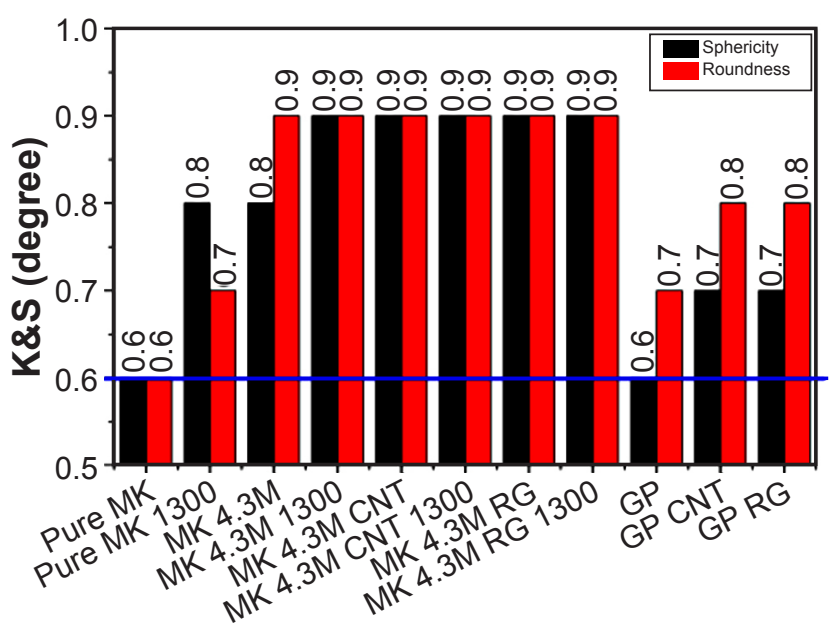

Figure 2: K\&S degree of the MK and GP samples. The blue line defines the K\&S standard degree limit (0.6). for MK based proppants [15]. It was possible to verify the texture of the spheres and, when compared to the commercial product that has a uniform and smooth texture, the need of a better finishing for the samples was evident [24]. This geometric factor can affect the drag of the material into the reservoir. At the same time, it can generate greater friction inside the reservoir and prevent backflow. Table III shows the results of sphericity and roundness by a Camsizer XT equipment. It shows that the MK $4.3 \mathrm{M}$ after heat-treatment $\left(1300{ }^{\circ} \mathrm{C} / 2 \mathrm{~h}\right)$ and the GP samples had similar values of SPHT and b/l. SPHT is the ratio between the area of the particle and its perimeter, defined by $4 \pi$.area/perimeter ${ }^{2}$, and $\mathrm{b} / \mathrm{l}$ is the ratio of the smallest to the largest particle diameter. Samples with values close to 1.0 have a higher degree of sphericity and roundness.

Turbidity analysis (NTU - nephelometric turbidity unit): the turbidity test was performed for all samples, using a Hanna HI98703-01 equipment by measuring the amount of transmitted light (and calculating the absorbed light) by particles in suspension. Fig. 3 shows that the MK samples without heat treatment and the geopolymer sample (GP) reached values above 250 NTU. Furthermore, proppants of geopolymers exceeded the threshold of 250 NTU. However, while adding carbon nanomaterials on GP matrix a huge decreasing of turbidity was observed. There was a relation between the turbidity test and the crushing test results: the lower NTU turbidity value, the greater was the strength of the material. Thus, the turbidity test (a non-destructive method) might help to predict the mechanical performance of the samples [25]. In the literature, the turbidity values obtained are $30 \mathrm{NTU}$ for geopolymer based proppant [15] while MK $4.3 \mathrm{M}$ of $\mathrm{NaOH}$ with $1300{ }^{\circ} \mathrm{C}$ sintering sample

Table III - Mean values of samples' sphericity and roundness from Camsizer XT equipment and K\&S from API RP 19 C standard.

\begin{tabular}{ccccc}
\hline \multirow{2}{*}{ Shape parameter } & \multicolumn{2}{c}{ MK 4.3 M with heat treatment } & \multicolumn{2}{c}{ GP (7 days cure) } \\
& Camsizer XT & K\&S & Camsizer XT & K\&S \\
\hline Mean value SPHT (sphericity) & 0.81 & 0.90 & 0.82 & 0.60 \\
Mean value b/l (roundness) & 0.73 & 0.90 & 0.77 & 0.70 \\
\hline
\end{tabular}




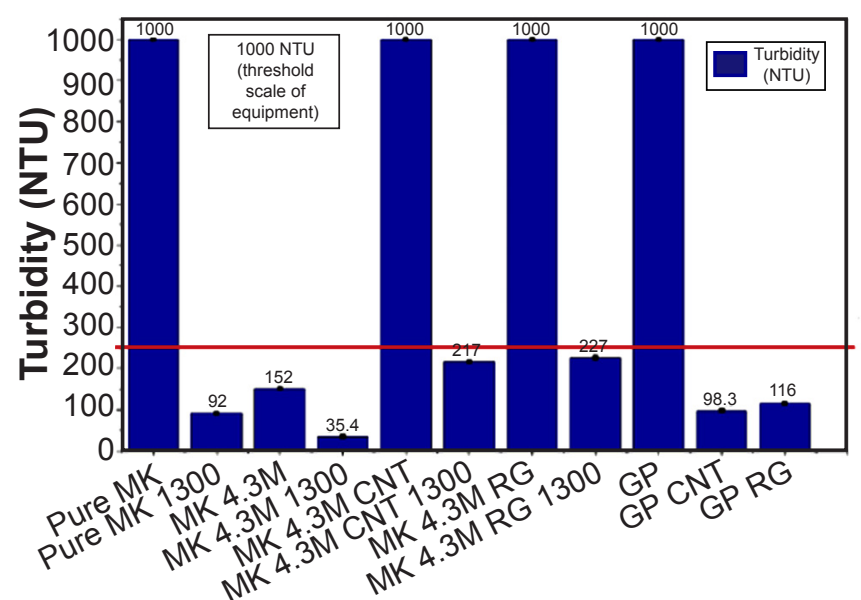

Figure 3. Turbidity bars plot of MK and GP samples. The red line defines the standard turbidity limit (250 NTU).

obtained a value of 35.4 NTU and for GP sample with CNT cured for 7 days was 98.3 NTU.

Crushing test from ISO 13503-2 and API RP 19C (K number): this test was performed following the standard with $3 \mathrm{~K}$ (3000 psi) crushing pressure. Fig. 4 shows the percentage value of fines generated in the crushing test for each sample analyzed. It was observed that the samples without heat treatment did not have significant strength, generating about $55 \%$ of fines, even for the samples activated with $\mathrm{NaOH}$ (MK samples). After the heat treatment, the MK samples increased about $40 \%$ in mechanical strength. We highlight the MK 4.3 M 1300 sample which reached about

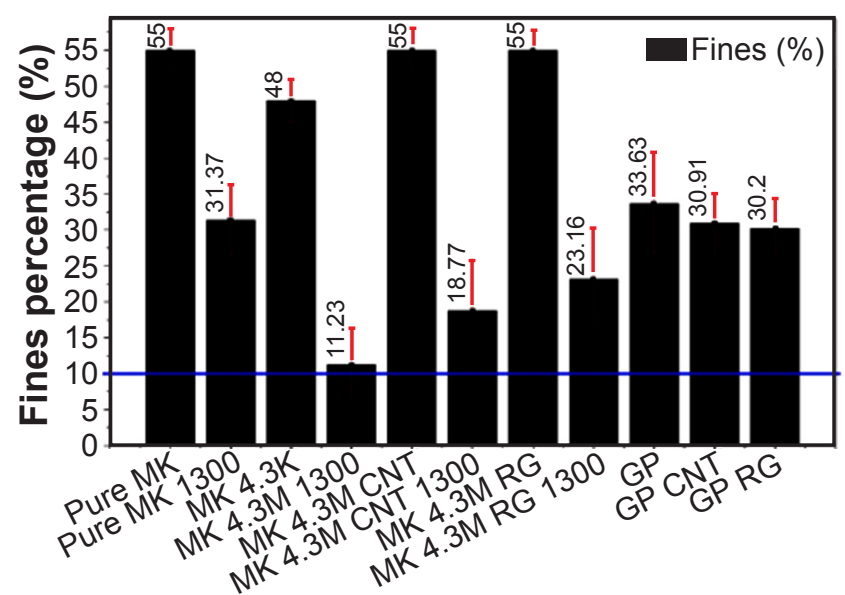

Figure 4: Results of 3 K (3000 psi) crushing test for MK and GP samples with and without heat treatment and nanocarbon materials. The blue line defines the standard limit (API RP $19 \mathrm{C}$ standard) of $10 \%$ of fines for $20 / 40$ mesh samples.
$11 \%$ of fines generated. For the GP samples, all presented an average generation of fines of $31 \%$ even though it was produced without heat treatment. The bulk density, performed by adapted procedure from API RP $19 \mathrm{C}$ standard, also presented a relationship with the mechanical strength because it indicated the densification level and the volume of pores in the sample. Table IV shows the bulk density of the samples. As shown in the crushing test graph (Fig. 4), the MK 4.3 M sample after heat treatment presented fewer fines generated with a higher bulk density of $1.24 \mathrm{~g} / \mathrm{cm}^{3}$ and the lower NTU value. It is also interesting to note that the density of the GP samples had an average bulk density of $0.92 \mathrm{~g} / \mathrm{cm}^{3}$ and presented lower fines generation while the MK samples without heat treatment had an average of 1.07 $\mathrm{g} / \mathrm{cm}^{3}$ and had a higher generation of fines. In this study, the GP samples cured for 7 days reached values, at the $3 \mathrm{~K}$ on

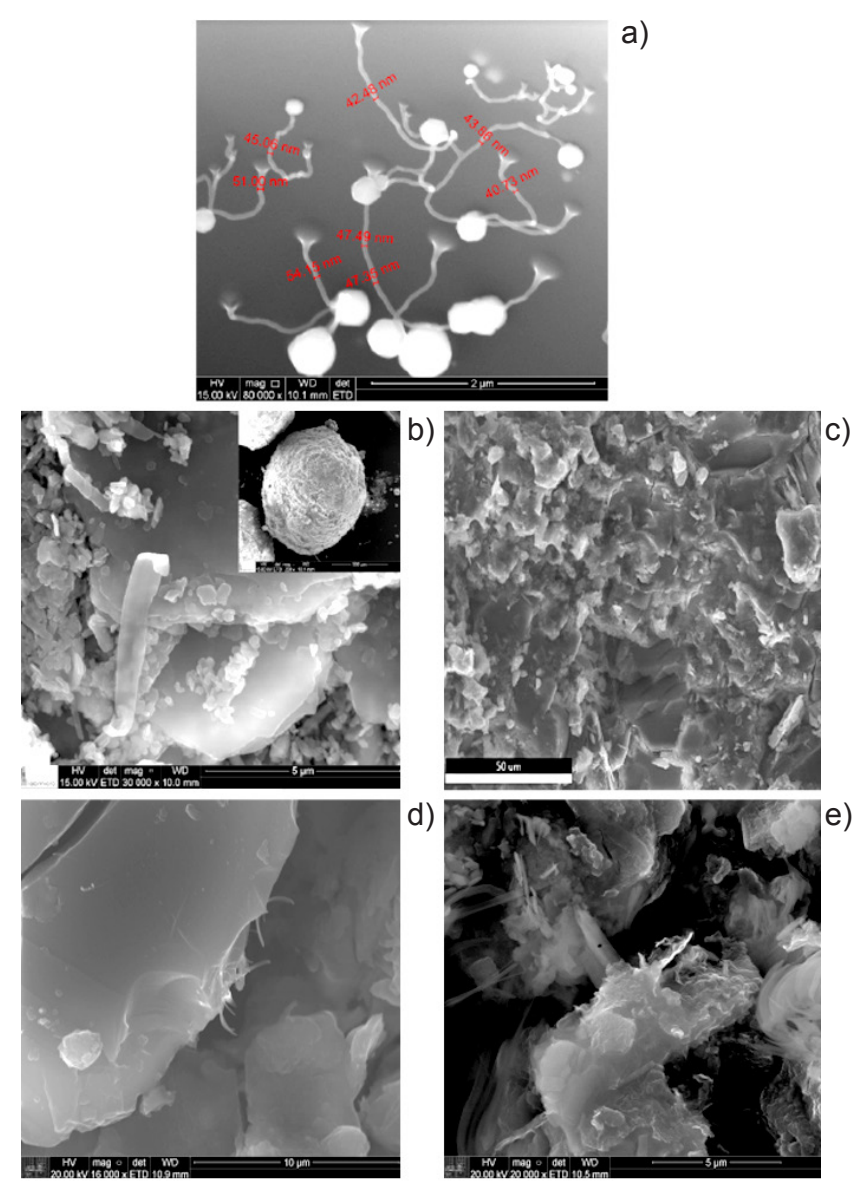

Figure 5: SEM micrographs of: a) MK 4.3 M sample with CNT after heat treatment; b) MK $4.3 \mathrm{M}$ sample with RG with heat treatment and a granule detail; c) GP sample; d) GP sample with CNT; and e) GP sample with RG.

Table IV - Bulk density $\left(\mathrm{g} / \mathrm{cm}^{3}\right)$ of the samples.

\begin{tabular}{cccccccc}
\hline Sample & MK pure & MK 4.3 M & $\begin{array}{c}\text { MK 4.3 M } \\
\text { CNT }\end{array}$ & $\begin{array}{c}\text { MK 4.3 M } \\
\text { RG }\end{array}$ & GP & \multirow{2}{*}{ GP CNT } & GP GR \\
\hline Without heat treatment & $1.03 \pm 0.12$ & $1.13 \pm 0.14$ & $1.08 \pm 0.13$ & $1.05 \pm 0.12$ & $0.80 \pm 0.10$ & $0.94 \pm 0.09$ & $0.95 \pm 0.12$ \\
With heat treatment & $1.01 \pm 0.15$ & $1.24 \pm 0.12$ & $1.11 \pm 0.13$ & $1.10 \pm 0.11$ & - & - & - \\
\hline
\end{tabular}



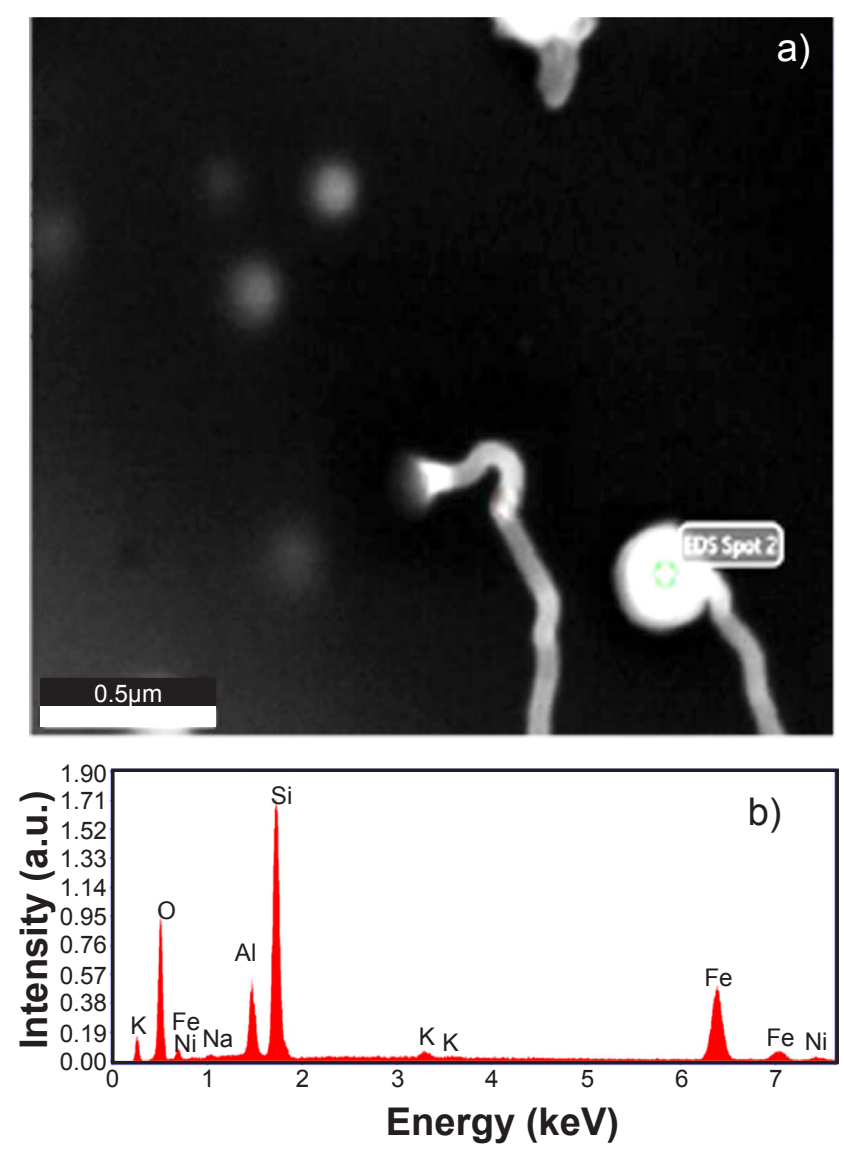

Figure 6: SEM micrograph of MK 4.3 M sample with CNT after heat treatment (a) and the EDS spectrum (b) from spot 2 indicated in (a).

crushing test, with an average of $31.5 \%$ of fines and a bulk density of $0.92 \mathrm{~g} / \mathrm{cm}^{3}$. In contrast, in the literature [15] the values of crushing test for a commercial geopolymer product could achieve $25 \%$ of fines at $5 \mathrm{~K}$ with $1.35 \mathrm{~g} / \mathrm{cm}^{3}$ of bulk density. It is important to notice that there are no scientific data for comparison with another metakaolin based proppant in the current bibliography.

Scanning electron microscopy (SEM): this analysis was performed to evaluate the surface and morphology of crushed samples, metakaolin, carbon nanotube and reduced graphene $[14,26]$ and to confirm the presence of the nanocarbon materials in the MK and GP matrix (Fig. 5) after the heat treatment. The presence of the nanomaterials was clearly observed when compared to the morphology of the pure materials. From Fig. 5a the carbon nanotube morphology is observed, with an average thickness of $54 \mathrm{~nm}$. The CNTs were directly bonded on the MK surface (Fig. 6). Fig. 5d shows the presence of silicate and aluminate-based material in the form of tapes in the matrix. The reduced graphene (RG) could be identified as a kneaded structure [14] in the center of the micrographs of MK 4.3 M RG (Fig. 5b) and GP RG (Fig. 5e) samples.

\section{CONCLUSIONS}

The proppant formulation based on metakaolin activated with $\mathrm{NaOH} 4.3 \mathrm{M}$ and sintered at $1300{ }^{\circ} \mathrm{C}$ for $2 \mathrm{~h}$ had the best mechanical performance. At the crushing test, it reached $3 \mathrm{~K}$ and thus it could be used as a ceramic synthetic proppant but having similar mechanical properties of silica sand. New compositions based on geopolymer (GP) was produced. GP samples showed $41 \%$ greater crushing strength with lower bulk density than the non-sintered MK samples. By SEM analysis it was observed that it is possible to incorporate CNT compounds bonded on matrix surface. Finally, the introduction graphene and CNT into GP proppant formulations improved the turbidity test results.

\section{ACKNOWLEDGMENTS}

Authors would like to thank ANP, EPUSP, Almatis do Brasil Ltd., Diaton Ltd., and Metacaulim do Brasil company.

\section{REFERENCES}

[1] M.B. Smith, C.T. Montgomery, Hydraulic fracturing, CRC Press, Boca Raton (2015).

[2] G.E. King, in: SPE Hydr. Fract. Technol. Conf. (2012).

[3] V.P.P. De Campos, E.C. Sansone, G.F.B.L. e Silva, Cerâmica 64, 370 (2018) 219.

[4] K. Patel, "EPA: Fracking does not lead to widespread water contamination", Ind. Min. (2015).

[5] B.J.R. Hellmann, B.E. Scheetz, W.G. Luscher, D.G. Hartwich, R.P. Koseski, Am. Ceram. Soc. Bull. 93, 1 (2014) 28.

[6] T.W. Urbanek, US10804868, "Proppants and their manufacture" (2004).

[7] M.N. Barreto, "Caracterização de materiais para garantir a condutividade de fraturas hidraulicamente induzidas em poços de petróleo e gás", Tese Dr., Pontif. Un. Catól. Rio Jan., Rio Janeiro (2010).

[8] M.A. Parker, K. Ramurthy, P.W. Sanchez, in: SPE East. Reg. Meet. (2012).

[9] M.G. Mack, C.E. Coker, in: SPE Annu. Tech. Conf. Exhib. 1 (2013) 1.

[10] R. Rediger, J. Petrella, M.J. Aron, B.W. Fennell, US8058213B2, "Increasing buoyancy of well treating materials" (2007).

[11] V.G. Peychev, S.Y. Pliner, S.F. Shmotyev, V.M. Sychev, RU2011138571A, "Manufacturing method of magnesiumsilicate proppant, and proppant itself" (2011).

[12] V.P.P. de Campos, S.M. Toffoli, D. Gouvea, G.F.B. Lenz e Silva, Mater. Sci. Forum 798-799 (2014) 503.

[13] X. Tian, B. Wu, J. Li, J. Hazard. Mater. 160, 2-3 (2008) 589.

[14] V.P.P. de Campos, G.A. Amaral Labat, E. Sansone, D. Gouvea, G.F.B. Lenz e Silva, Mater. Sci. Forum 912 (2018) 251.

[15] E. Allouche, C. Montes, J.J. Rome, M. Higgins, Alchemy Geopolymer Solutions, Ruston (2014).

[16] F. Liang, M. Sayed, G.A. Al-Muntasheri, F.F. Chang, L. Li, Petroleum 2, 1 (2016) 26.

[17] M. O'Driscoll, I. Clarke, in: CMA $117^{\text {th }}$ Nat. West. Min. 
Conf., Ind. Min. Forum. Res. (2015).

[18] T. Kowald, in: Int. Symp. Ultra High Perf. Concr. (2004) 195.

[19] A. Cwirzen, Adv. Cem. Res. 2 (2008) 65.

[20] A.G. Goldoni, L. Pandolfo, Geopolímero com incorporação de nanotubos de carbono, Novas Ed. Acad. (2014).

[21] M. Saafi, K. Andrew, P.L. Tang, D. McGhon, S. Taylor, M. Rahman, S. Yang, X. Zhou, Constr. Build. Mater. 49 (2013) 46.

[22] M. Saafi, L. Tang, J. Fung, M. Rahman, F. Sillars, J.
Liggat, X. Zhou, Smart Mater. Struct. 23, 6 (2014) 65006. [23] J. Davidovits, Geopolymer chemistry and applications, Inst. Géopolym. (2015).

[24] S. Curimbaba, G.W.K.P. Cortes, G.P. Cortes, US7954548B2, "Proppant for hydraulic fracturing of oil and gas wells" (2003).

[25] I. Saaid, D. Kamat, S. Muhammad, Am. Int. J. Contemp. Res. 1 (2011) 37.

[26] V.P.P. de Campos, G.A. Amaral Labat, D. Gouvea, G.F.B. Lenz e Silva, Mater. Sci. Forum 930 (2018) 37.

(Rec. 29/09/2018, Rev. 13/11/2018, Ac. 04/12/2018) 